\title{
The Effect of Teacher Talk in EFL Classrooms: The Nonuse or Use of Learners' L1 by an Instructor
}

\author{
Chiyo Myojin \\ Department of Core Studies, Faculty of Technology, \\ Kochi University of Technology, \\ Kami City, Kochi Prefecture, Japan \\ e-mail: myojin.chiyo@kochi-tech.ac.jp
}

\begin{abstract}
This study examines the effect of the variation of teacher talk on EFL learners' performance, especially the one related to listening comprehension skills, by chronologically observing a Japanese first language (L1) instructor's classrooms at a university.
\end{abstract}

Key words: teacher talk, first language, EFL classrooms, listening comprehension skills, utterances, functions

It has always been an interesting question how much effect the variation of teacher talk in EFL classrooms on learners' performance, especially on listening comprehension skills. Of greater interest to EFL classroom researchers is the question whether or not instructors should use their learners' L1 in EFL classrooms, especially in culturally homogeneous environments such as Japan where the majority is monolingual. However, there is little discussion on the issue of whether instructors' use of their learners' L1 in EFL classrooms would be more helpful for the learners' acquisition of English or whether an English-only teaching environment would be more efficient in EFL classrooms.

There are still some researchers who advocate that the use of Japanese by an instructor in EFL classrooms would be beneficial for the Japanese learners. First, according to Atkinson (1993), communicative methodology can be integrated with selective and limited use of L1. He points out that, although it may not be simple to talk of a right balance or a perfect model for using L1, it can be a valuable resource if it is used at appropriate times and in appropriate ways. Weschler (1997) also suggests using L1 for warm-up brainstorming. Abstract words or expressions that are difficult to explain in the second language (L2) are better translated in L1. Cole (1998) concluded that L1 may be used from introductory to upper-intermediate http://www.petra.ac.id/ puslit/journals/dir.php?DepartmentID $=I N G$ 
level, particularly at lower levels where translating individual words, explaining grammar use, and facilitating complex instructions in L1 can save time and anguish. However, these researchers do not mention specifically how much Japanese and English should be used in class for efficient EFL classroom teaching, although they point out more or less when and how the L1 should be used.

Chaudron (1988) and Greene and Myojin (1998, 1999) descriptively investigated the use of learners'L1 and target language. They analyzed teacher talk in second language classrooms into the pedagogical functions such as explanations, demonstrations, directions, elicitations, follow-ups, and etcetera. However, their research did not attempt to investigate the effect of variation in the use of learners' L1 by EFL teachers on the learners' performance.

Critchley (1999) investigated whether or not students need bilingual support from their native-speaker English teachers, by conducting a survey of students' opinions on EFL classes at a Japanese university. He also examined where and why bilingual support should be given if the students believe it is needed. As a result, $87 \%$ of the learners indicated that they preferred the teacher to use Japanese occasionally in class, while $9 \%$ expressed a preference for an English-only environment, and only 4\% preferred a significant amount of Japanese use in class. Next, the results of the survey showed that the mean English-Japanese ratio preference is $80 \%$ English to 20\% Japanese. Although there was no indication of the specific number of students, the majority indicated that the use of Japanese in class should be limited, and the class should be conducted primarily in English. To be precise, the respondents asserted that they needed some Japanese support only when they could not understand what they considered to be essential aspects of the lesson, especially concerning tests and homework. This is because they were afraid that being in an English-only environment might be a waste of time if they could not follow what was happening in class. Critchley concluded that the English-only paradigm may not be appropriate for Japanese contexts.

However, Ur (1999) emphasizes that it is more important for L2 learners of English to have plenty of opportunities to listen to their teacher's English than to have time to practice the language skills on their own. She also asserts that, because language is an arbitrary set of symbols, it cannot possibly be learnt by discovery or imagination on the part of learners. Therefore, she suggests that English classes should be filled with a lot of 
informal teacher-chat in English, which is a conveniently available and also excellent listening material. It is easy to listen to, since it is 'live' and 'personal'.

Kumabe (1998) also pointed out in "English Lesson Seminar" in Tokyo that, since there were very few opportunities for students to use and listen to English outside the classroom, the classroom situation itself might be regarded as a real world so the instructor should try to use as much English as possible in EFL classrooms. He added that we should not waste such a good opportunity to use English in a classroom as if it was the real world. Mochizuki (1996) also emphasizes the importance of an instructor's English teacher talk rather than audio materials in classrooms.

Judging from the above linguists' assertions, it seems to be speculated that, although an English-only learning environment is not appropriate in Japan, it is still important for Japanese learners of English to be exposed to as much English as possible in order to improve their English skills.

Therefore, my study examined the effect of the variation of teacher talk on EFL learners' performance, especially the one related to listening comprehension skills, by chronologically observing a Japanese L1 instructor's classrooms at a university. Is it really the case that the more English an instructor uses as teacher talk in classrooms, the more the students' English listening comprehension skills will improve within only a few months, or will there be no effect on the students' listening comprehension skills even after they have been exposed to 90\% English in class? In addition, I conducted a survey of student opinions of four English classes, where more than $90 \%$ of teacher talk consisted of English. The survey inquired whether or not the students had experienced such an almost-English-only class before, and how they felt about their current English classes where more than 90\% of teacher talk consisted of English.

Hypothesis: An increase in the use of English by the instructor in the classroom will result in the improvement in the learners' listening comprehension skills.

\section{METHDOLOGY}

The effectiveness of nonuse of learners' L1 by an instructor in EFL classrooms was investigated by a quasi experiment and a survey study. This research observed an instructor's teacher talk and the listening comprehension skills of two groups of her students across two months' 
lessons. In addition, the English classes' questionnaire survey of students was conducted in four different classes where English teacher talk was more than $90 \%$ of the entire teacher talk; including one class which participated in the research on teacher talk and students' performance, mentioned above.

\section{Subjects}

The subjects were divided into two groups: group A consisted of twenty-three freshmen (four females and nineteen males) at a technology university in Japan; while group B consisted of twenty-five freshmen (five females and twenty males) at the same university (there were originally twenty-six, but one was absent for the second test). They were all technology majors. There were totally three classes of the first-year students who were enrolled in the Oral English course by the alphabetical order of their last names. The students involved in this experiment were in the two of the three classes. The students' English levels in the two groups were assumed to be almost equal and this was proved by the results of the pretests.

\section{Instructor}

The instructor was Japanese, and had taught JFL in the US for ten years and EFL in Japan for nine years.

\section{English Taught in Class}

The frequency of meeting of both groups was twice a week, one hour each. The same teaching materials and lesson contents were used in both groups. That is, the instructor taught both groups Oral English in a variety of situations such as Introducing Yourself, Meeting Others, Greeting, Telephone Conversation, Thanking People, Shopping etcetera. Different teacher talk utterances in the two groups' lessons were intentionally made, not unconsciously occurred. However, the important point was that the degrees of exposure to English were intentionally designed to be different in the two groups: that is, Group A students were exposed to 53\% English and 47\% Japanese, whereas Group B students were exposed to 93\% English and 7\% Japanese (See "FINDINGS AND DISCUSSION" below). A practice for the listening comprehension test was not especially done in class during the experiment period. 


\section{Test and Survey Used for This Experiment}

The test used for the experiment was the modified test of pre-second exam administered by the Japan English Proficiency Test Association, which is carried out three times a year nationwide (Appendix C). Only the listening comprehension part of the exam was used for this experiment. It consisted of three parts: Part I included five two-person-conversation questions; Part II also had five two-person-conversation type questions, but each conversation was a little longer than those in Part I; Part III contained ten quite long statement-type questions. Next, the English classes' questionnaire survey of students (See Appendix B) was administered in four different almost-English-only classes by four different instructors, that is, three native speakers of English and one Japanese. One of the four classes was the Group B class in this study, which was taught by the Japanese instructor. Before the survey was conducted, the three native speakers of English reported that English teacher talk in their classes was more than $90 \%$ of the entire teacher talk.

Null Hypothesis: For the purpose of research, the null hypothesis was formulated as follows: An increase in the use of English by the instructor in the classroom will not result in the improvement in the learners' listening comprehension skills.

\section{Procedures}

For the investigation into the students' performance, the same listening comprehension test was administered individually to Group A and Group $\mathrm{B}$, once at the beginning of the quarter, and again at the end of the quarter after fifteen hours' lessons (i.e. seven weeks later). The same test was given to both groups and each student's test results were analyzed. As for English and Japanese teacher talk, the instructor was videotaped in a natural setting during two complete one-hour lessons during the quarter; one with Group A and one with Group B. Then, data were collected from observations of the videos and analysis of written transcriptions of the videos. In more detail, the exact numbers of English teacher- talk utterances and words as well as Japanese ones were counted from the written transcriptions of the videos. Also, the teacher talk utterances were analyzed into the pedagogical functions such as demonstrations, explanations, directions, elicitations, and 
follow-ups. As for the English classes' survey, the students' responses to the six questions about their English-only classes (See Appendix B) were analyzed.

\section{FINDINGS AND DISCUSSION}

\section{Teacher Talk Results}

Table 1 shows the results of the observation of the instructor's teacher talk in the one-hour lessons with Group A and Group B.

Table 1. Teacher Talk Utterances: Number, Length and Function

\begin{tabular}{lll}
\hline & Group A & Group B \\
\hline Utterances & & \\
Total Utterances & 853 & 809 \\
Eng Utterances & 452 & 754 \\
Eng Utt / Total Utt & $\underline{\mathbf{5 3 \%}}$ & $\underline{\mathbf{9 3} \%}$ \\
Jpn Utterances & 401 & 53 \\
Jpn Utt/Total Utt & $\underline{\mathbf{4 7} \%}$ & $\underline{\mathbf{7 \%}}$ \\
Length & & \\
Total words & 5018 & 4440 \\
Total Eng Words & 2633 & 4204 \\
Eng Utt Length & $5.8 \mathrm{wpu}$ & $5.6 \mathrm{wpu}$ \\
Total Jpn Words & 2385 & 236 \\
Jpn Utt Length & $5.9 \mathrm{wpu}$ & $4.4 \mathrm{wpu}$ \\
Eng Functions & & \\
Demonstrations & $205(45 \%)$ & $157(21 \%)$ \\
Explanations & $73(16 \%)$ & $146(19 \%)$ \\
Directions & $96(21 \%)$ & $264(35 \%)$ \\
Elicitations & $62(14 \%)$ & $83(11 \%)$ \\
Follow Ups & $16(4 \%)$ & $74(10 \%)$ \\
Jpn Functions & & \\
Translations & $44(11 \%)$ & $4(6 \%)$ \\
Explanations & $180(45 \%)$ & $25(43 \%)$ \\
Directions & $166(41 \%)$ & $14(25 \%)$ \\
Elicitations & $7(2 \%)$ & $5(8 \%)$ \\
Follow Ups & $4(1 \%)$ & $4(6 \%)$ \\
\hline
\end{tabular}


The data show that the instructor spoke English 93\% of the total teacher talk time with Group B, but only 53\% with Group A. The data also indicate that the proportions of English Explanations and Directions used for Group B are twice and almost three times as high, respectively, as for Group A. On the other hand, the instructor used about seven times and eight times as much Japanese for both Explanations and Directions, respectively, with Group A as with Group B.

\section{Students' Score Results}

For the results of the fist and second listening comprehension tests by both experimental groups, each student's results were analyzed as shown in Appendix A. First, the results indicate that there were eight students in Group B who were able to score their second test over $20 \%$ more than their first test, whereas there were only two students in Group A for such improvement. Table 2 shows the mean scores of the whole test by group.

\section{Table 2. Mean Scores of the Whole Test}

\begin{tabular}{ccccc}
\hline $\begin{array}{c}\text { (Teacher Talk }=\text { 53\%Eng. \& 47\% } \\
\text { Japanese) } \\
\text { Group A }\end{array}$ & $\begin{array}{c}\text { (Teacher Talk=93\% Eng. \& 7\% } \\
\text { Japanese) } \\
\text { Group B }\end{array}$ & \\
\hline $\begin{array}{ccccc}\text { (results out of 100) } \\
\text { 1st test } \\
\text { 2nd test } \\
\text { improvement } \\
49\end{array}$ & $\underline{\text { mean }}$ & $\underline{1 \text { st test }}$ & $\begin{array}{c}\text { 2nd test } \\
\text { improvement } \\
45\end{array}$ & $\underline{\text { mean }}$ \\
\hline
\end{tabular}

Comparing the mean scores of the first and second tests by both groups, the mean score of the second test performed by Group B is 32\% higher than that of the 1st test, while the improvement by Group A is only $10 \%$.

Next, the mean scores of the two tests by part were analyzed for both of the groups as shown in Table 3. 


\section{Table 3. Mean Scores by Part}

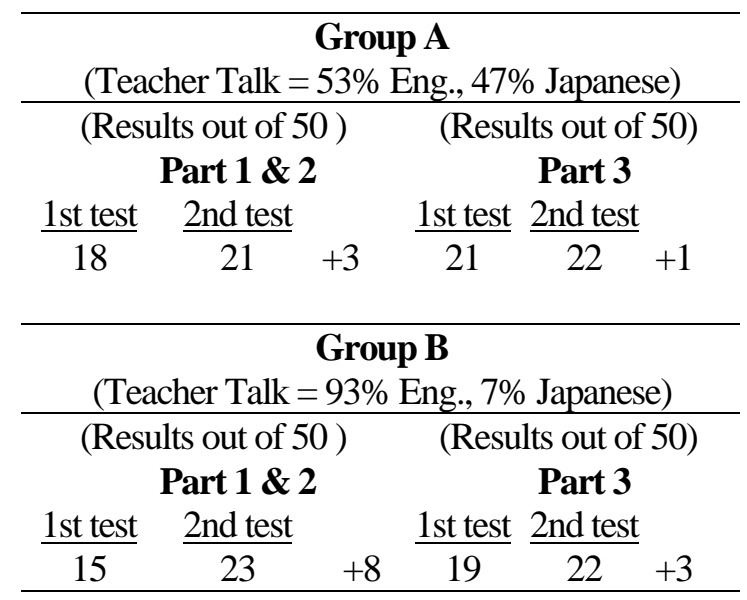

From these results, it was found that both groups showed a lot more improvement in their performance for the shorter conversation-style questions in Parts I and II than for the longer statement-type questions in Part III. Group B's performance for Parts I and II was improved by as much as $50 \%$ on average, although the improvement for Part III was only $16 \%$. For the Group A’s performance, the increase in Parts I and II was $16 \%$, but only $5 \%$ for Part III.

\section{Survey Results}

With the English Classes' Survey, the results indicate that most of the students had very few opportunities (42\% for "almost never" and 26\% for "never") to be exposed to English teacher talk in classrooms in high school. (See Appendix B 2). The survey results also show that, even though nearly $70 \%$ of the students had not been accustomed to English-only environments like that at the university, 57\% of the students now felt comfortable in such a classroom setting, 35\% were not sure about it, and only $6 \%$ could not enjoy the class. To the question "How did or do you feel in class?", 55\% of the students chose the answer "In the beginning, I was nervous, but now I am more relaxed". Regarding the question on whether they think English-only classes help them to learn English, 93\% of the students thought they were helpful. Table 4 below demonstrates the 
comparison between the learners' comprehension ability of teacher talk based upon the survey's self-report and the answers of the question about helpfulness of English. It appears that the more the students understand teacher talk, the more they believe that English-only classes are helpful.

Table 4. The Comparison between the Learners' Comprehension Ability of Their Teacher's English and Their Responses to the Question, "Do you think English-only classes help you to learn English?”

\begin{tabular}{lccc}
\hline \multicolumn{3}{c}{ (percentage of how much the learners understood their teacher’s English) } \\
& $>40 \%$ & $40 \sim 80 \%$ & $80 \% \sim$ \\
\hline Yes, they are very helpful & $23 \%$ & $36 \%$ & $75 \%$ \\
Yes, they are a little helpful & $26 \%$ & $38 \%$ & $25 \%$ \\
They are so-so & $43 \%$ & $19 \%$ & 0 \\
No, they are not very helpful & $5 \%$ & $5 \%$ & 0 \\
No, they are not helpful at all & $3 \%$ & $2 \%$ & 0 \\
\hline
\end{tabular}

\section{CONCLUSION}

This experimental study investigated how much effect the nonuse of Japanese learners' L1 by an instructor in an EFL classroom had on the students' listening comprehension skills. The findings of this study have led to several conclusions:

First, the less Japanese and the more English an instructor used for teacher talk in EFL classrooms, the more the learners' listening comprehension skills of English were improved after only two months' lessons.

Second, the effectiveness of the learners' listening comprehension skills was found to improve in short conversation exercises to a greater extent than in longstatement-style conversation exercises:

Finally, it seems to be the case that a great number of the students who had never, or almost never had, an opportunity to listen to 90\% English teacher talk were able to improve their listening comprehension skills, even in quite a short period, once they had an opportunity to be exposed to plenty of English teacher talk in classrooms at the university. From the findings it could be seen that the null hypothesis was rejected. Therefore, my study seems to confirm the hypothesis that increasing the amount of English teacher talk leads to the improvement in students' English listening comprehension skills. 
However, there are still several questions raised by this study to be solved through further research. First, are there any factors that might contribute to the results of students' listening comprehension tests other than the degrees of exposure to English in class? Might the Group B students have had more serious attitudes towards practicing listening comprehension exercises than the Group A students, so that the former group had practiced the skills outside the classroom by themselves more than the latter? In other words, the factor of the students' exposure to English outside classrooms seems to be an important variable for this research, but it is not controllable and hard to be investigated, which might become one of the limitations of this research. The second question is on how much effect the lesser use of Japanese by the instructor produced on the students' English skills other than listening comprehension. Might it be the case that such an almost-English-only environment could cause problems with the students' understanding of essential aspects of the lesson, so that their skills other than listening comprehension might become weaker?

This study did not compare the improvement of the learners in relation to their levels of English teacher talk at high school. Perhaps the use of an almost-English-only classroom environment only benefits those who have previously been exposed to it.

Furthermore, since this study did not investigate the effectiveness of a 100\% English-only learning environment, we still do not know whether or not it might lead to a greater improvement in learners' English skills than in a learning environment where less English is used. Further research on this will be needed in order to determine the most effective EFL learning environment to enable Japanese students to improve their listening comprehension skills.

\section{REFERENCES}

Atkinson, D. (1993). Teaching monolingual classes. London: Longman.

Burden, P. (2000). The use of the students' mother tongue in monolingual English "Conversation" classes at Japanese universities. The Language Teacher, 24(6), 5-10.

Chaudron, C. (1995). Teacher talk in second language classrooms: Second language classrooms. Cambridge: Cambridge University Press. 
Critchley, M. (1999). Bilingual support in English classes in Japan: A survey of student opinions of L1 used by foreign teachers. The Language Teacher, 23(9), 3-13.

Cole, S. (1998). The use of L1 in communicative English classrooms. The Language Teacher, 22(12), 11-13.

Greene, D., \& Myojin, C. (1998). The use of learners' L1 by EFL instructtors. Paper presented at AAAL (American Association of Applied Linguistics) Conference, Seattle, WA, USA.

(1999). The use of Learners' L1 by EFL instructors: Attitudinal surveys and case study. Paper presented at AILA 99 Conference, Tokyo, Japan.

Kumabe, N. (1998). Video ni yoru jugyou kenkyuu to kyoogi. [Research and discussion on English classes, showing a video of them] at Eigo Jugyo Kenkyu Gakkai. [English class research seminar], Tokyo.

Mochizuki, A. (1996). Watashi no Eigo Jugyo. [My English classes]. Tokyo: Taishuukan Publishing Company.

Ur, P. (1999). Teaching listening comprehension. Cambridge: Cambridge University Press.

Weschler, R. (1997). Uses of Japanese (L1) in the English classroom: Introducing the functional -translation method. The Internet TESL Journal, 3(11). Retrieved June 15, 2005, from http://iteslj.org/ Articles/Weschler-UsingL1.html 


\section{APPENDIX A}

\section{The Results of the Test (Total scores)}

Group A

\begin{tabular}{|c|c|c|c|}
\hline & test & & \\
\hline (1) & $20 / 100$ & 30 & +1 \\
\hline (2) & 45 & 40 & \\
\hline (3) & 50 & 60 & \\
\hline (4) & 35 & 55 & \\
\hline 5) & 40 & 35 & \\
\hline 6) & 55 & 70 & \\
\hline (7) & 30 & 35 & \\
\hline (8) & 45 & 45 & \\
\hline (9) & 40 & 40 & \\
\hline 0) & 35 & 30 & \\
\hline 1) & 25 & 35 & + \\
\hline 2) & 45 & 50 & \\
\hline 3) & 45 & 55 & +1 \\
\hline 14) & 35 & 30 & \\
\hline (15) & 55 & 50 & \\
\hline 16) & 60 & 65 & \\
\hline 17) & 25 & 15 & -1 \\
\hline 8) & 30 & 40 & +1 \\
\hline 9) & 40 & 55 & +1 \\
\hline 20) & 45 & 30 & 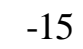 \\
\hline 1) & 35 & 40 & \\
\hline 2) & 30 & 35 & \\
\hline 3) & 25 & 60 & \\
\hline
\end{tabular}

n

\section{Group B}

(24) $\frac{1}{1 \text { st }} \frac{\text { test }}{5 / 100} \frac{\text { 2nd }}{25}+20$

(25) $45 \quad 55 \quad+10$

(26) $\quad 45 \quad 30 \quad-15$

$\begin{array}{llll}(27) & 25 & 65 & +40\end{array}$

(28) $35 \quad 45 \quad+10$

(29) $\quad 30 \quad 40 \quad+10$

$\begin{array}{llll}\text { (30) } & 40 & 55 & +15\end{array}$

(31) $\quad 35 \quad 30 \quad-5$

(32) $\quad 35 \quad 45 \quad+10$

(33) $\quad 55 \quad 90 \quad+35$

(34) $45 \quad 50 \quad+5$

(35) $40 \quad 40 \quad 0$

(36) $\quad 25 \quad 35 \quad+10$

$\begin{array}{llll}\text { (37) } \quad 35 & 50 \quad+15\end{array}$

(38) $\quad 20 \quad 40 \quad+20$

(39) $25 \quad 35 \quad+10$

(40) $25 \quad 5 \quad-20$

$\begin{array}{llll}\text { (41) } & 25 & 15 & -10\end{array}$

(42) $\quad 25 \quad 30 \quad+5$

$\begin{array}{llll}\text { (43) } 40 & 60 & +20\end{array}$

(44) $\quad 40 \quad 60 \quad+20$

(45) $\quad 40 \quad 60 \quad+20$

(46) $\quad 65 \quad 60 \quad-5$

$\begin{array}{lll}\text { (47) } & 20 \quad 55 & +35\end{array}$

\begin{tabular}{lllr}
$(48)$ & 25 & 35 & +10 \\
\hline mean & 34 & $45+11 / 100$
\end{tabular}




\section{The Results of the Test (by Part)}

\section{Group A}

Part $1 \& 2$

$\underline{1}^{\text {st }}$ test $\underline{2}^{\text {nd }}$ test

(1) $5 \quad \begin{array}{lll}10 & +5\end{array}$

(2) $20 \quad 15 \quad-5$

(3) $25 \quad 25 \quad 0$

(4) $15 \quad 25 \quad+10$

(5) $15 \quad 15 \quad 0$

(6) $35 \quad 40 \quad+5$

(7) $20 \quad 20 \quad 0$

(8) $15 \quad 20 \quad+5$

(9) $20 \quad 25 \quad+5$

(10) $30 \quad 25 \quad-5$

$\begin{array}{llll}\text { (11) } & 5 & 15 & +10\end{array}$

(12) $25 \quad 25 \quad 0$

(13) $15 \quad 10 \quad-5$

(14) $5 \quad 15+10$

(15) $30 \quad 25 \quad-5$

(16) $25 \quad 40 \quad+15$

(17) $10 \quad 5 \quad-5$

(18) $10 \quad 10 \quad 0$

(19) $25 \quad 35+10$

(20) $15 \quad 10 \quad-5$

(21) $15 \quad 25+10$

$\begin{array}{llll}\text { (22) } & 15 & 20 & +5\end{array}$

$\begin{array}{lllr}(23) & 10 & 30 & +20 \\ \text { mean } & 18 & 21 & +3 / 50\end{array}$

\section{Part 3 \\ $1^{\text {st }}$ test $\underline{2}^{\underline{\text { nd }}}$ test}

(1) $15 \quad 20 \quad+5$

(2) $25 \quad 25 \quad 0$

(3) $25 \quad 35+10$

(4) $20 \quad 30 \quad+10$

(5) $25 \quad 20 \quad-5$

(6) $\quad 20 \quad 30 \quad+10$

(7) $10 \quad 15 \quad+5$

(8) $\quad 30 \quad 25 \quad-5$

(9) $\quad 20 \quad 15 \quad-5$

(10) $5 \quad 5 \quad 0$

(11) $20 \quad 20 \quad 0$

(12) $20 \quad 25 \quad+5$

(13) $\quad 30 \quad 45 \quad+15$

(14) $\quad 30 \quad 15 \quad-15$

(15) $25 \quad 25 \quad 0$

(16) $\quad 35 \quad 25 \quad-10$

(17) $15 \quad 10 \quad-5$

(18) $\quad 20 \quad 30 \quad+10$

(19) $15 \quad 20 \quad+5$

(20) $30 \quad 20 \quad-10$

(21) $\quad 20 \quad 15 \quad-5$

(22) $15 \quad 15 \quad 0$

\begin{tabular}{lllr}
$(23)$ & 15 & 30 & +15 \\
\hline mean & 21 & 22 & $+1 / 50$
\end{tabular}




\section{The Results of the Test (by Part)}

\section{Group B}

\begin{tabular}{|c|c|c|c|c|c|c|c|}
\hline & Part & & & & Par & & \\
\hline & est & & & & est & & \\
\hline (24) & 0 & 5 & +5 & (24) & 5 & 20 & +15 \\
\hline (25) & 25 & 35 & +10 & (25) & 20 & 20 & 0 \\
\hline (26) & 25 & 15 & 0 & (26) & 30 & 15 & -15 \\
\hline (27) & 10 & 30 & +20 & (27) & 15 & 35 & +20 \\
\hline (28) & 20 & 25 & +5 & (28) & 15 & 20 & +5 \\
\hline (29) & 15 & 15 & 0 & (29) & 15 & 25 & +10 \\
\hline (30) & 15 & 30 & +15 & (30) & 25 & 30 & +5 \\
\hline (31) & 10 & 15 & +5 & (31) & 25 & 15 & -10 \\
\hline (32) & 5 & 30 & +25 & (32) & 30 & 15 & -15 \\
\hline (33) & 25 & 40 & +15 & (33) & 30 & 50 & +20 \\
\hline (34) & 20 & 25 & +5 & (34) & 25 & 25 & 0 \\
\hline (35) & 25 & 25 & 0 & (35) & 15 & 15 & 0 \\
\hline (36) & 20 & 25 & +5 & (36) & 5 & 10 & +5 \\
\hline (37) & 15 & 25 & +10 & (37) & 20 & 25 & +5 \\
\hline (38) & 5 & 20 & +15 & (38) & 15 & 20 & +5 \\
\hline (39) & 15 & 20 & +5 & (39) & 10 & 15 & +5 \\
\hline (40) & 15 & 5 & -10 & (40) & 10 & 0 & +10 \\
\hline (41) & 19 & 5 & -5 & (41) & 15 & 10 & -5 \\
\hline (42) & 0 & 10 & +10 & (42) & 25 & 20 & -5 \\
\hline (43) & 15 & 20 & +5 & (43) & 25 & 40 & +15 \\
\hline (44) & 15 & 30 & +15 & (44) & 25 & 30 & +5 \\
\hline (45) & 15 & 40 & +25 & (45) & 25 & 20 & -5 \\
\hline (46) & 20 & 35 & +5 & (46) & 35 & 25 & -10 \\
\hline (47) & 20 & 25 & +5 & (47) & 0 & 30 & +30 \\
\hline (48) & 10 & 15 & +5 & (48) & 15 & 20 & +5 \\
\hline hean & 15 & 23 & $+8 / 50$ & mean & 19 & 22 & $-3 / 50$ \\
\hline
\end{tabular}




\section{APPENDIX B}

\section{English Classes' Survey}

1. How much of the teacher's lecture in English did you understand? more than $90 \%$

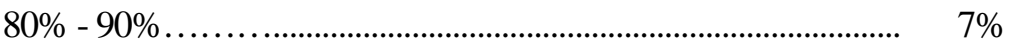

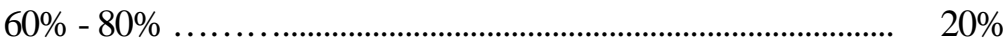

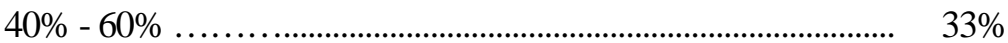

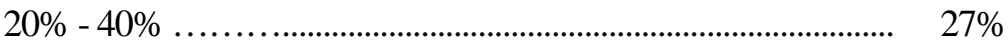

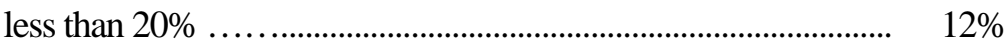

2. Have you ever had English classes which use English lecture like this before?

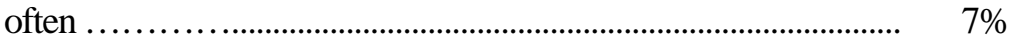

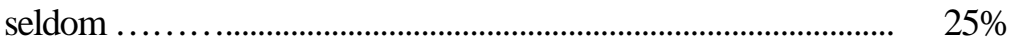

Where? \& How?

from native speakers in high school .................................... 50\%

oral communication class in high school .............................. 37\%

at an English conversation school ..................................... 13\%

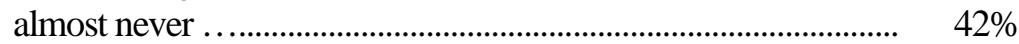

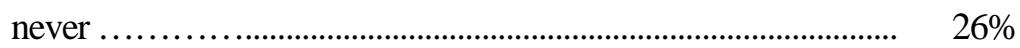

3. What do you think about class in which the teacher uses only English?

From the beginning, I enjoyed the class very much ............ 21\%

From the beginning, I enjoyed the class a little ............... $19 \%$

Only now, I am beginning to enjoy the class ......................... 17\%

Even now, I am not sure if I enjoyed the class or not ........... $\quad 35 \%$

I cannot enjoy the class so much .......................... $4 \%$

I cannot enjoy the class at all .............................. $2 \%$

No answer ...................................................... 2\%

4. How did or do you feel in the class?

I have never been nervous and embarrassed in the class ............. . 11\%

In the beginning, I was nervous, but now I am more relaxed ..... 55\%

In the beginning and even now I am nervous .................. $\quad 6 \%$

Even now, I m very nervous and embarrassed ................. $\quad 3 \%$ 
5. Do you think English-only classes help you to learn English?

Yes, they are very helpful ....................................................... 33\%

Yes, they are a little helpful ......................................................... 33\%

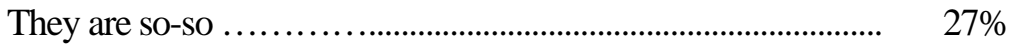

No, they are not very helpful ..................................................... $5 \%$

No, they are not helpful at all ....................................................... $1 \%$

No answer ................................................................. $1 \%$

6. Please explain why you answered as you did in (5);

(5)"Do you think English-only-classes help you to learn English?"

+ a desire to communicate better in English for future career ... 25\%

+ a desire to communicate better in English for travel .......... $\quad 17 \%$

+ enjoyment of English.................................... $9 \%$

+ opportunity to hear and speak "real" English in context ...... $\quad 6 \%$

+ need to learn English as the world language for computers... $\quad 5 \%$

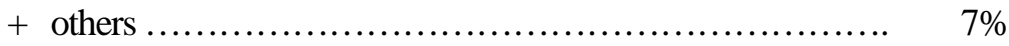

- inability to understand.................................... $11 \%$

- no opportunity to use English.............................. $\quad 5 \%$

- too short a time for English learning........................ $\quad 3 \%$

- shyness................................................... $3 \%$

- forced to speak........................................... $2 \%$

- others................................................. $6 \%$ 


\section{APPENDIX C}

\section{Examples of the Test}

Part 1 (totally 5 questions)

e.g. Question (1)

(you hear the following two persons' conversation once)

A: Do you remember my brother Bill?

B: Yes, I met him at your house once or twice.

A: Well, he won a medal in the swimming tournament yesterday.

Answer: (you choose the correct response to the last statement from the choices written in the answer sheet)

1. That's great. Congratulations!

2. Twice.

3. I remembered the swimming tournament.

4. I had fun swimming at your house yesterday.

Part 2 (totally 5 questions)

e.g Question (6) (you hear the following two persons' conversation once)

A: I went to the dentist's yesterday because I had a toothache.

B: Oh, Emily, will the dentist pull out your tooth?

A: Not right away, but maybe over spring vacation.

In the meantime, the dentist said I need to brush my teeth very carefully.

Question: What did the doctor tell Emily? (you hear a question once)

Answer: (you choose the correct answer from the choices written in the answer sheet)

1. Her tooth needs to be pulled out right away.

2. She shouldn't wait until spring vacation.

3. She should brush her teeth well.

4. Her toothache is serious.

$\underline{\text { Part } 3}$ (totally 10 questions)

e.g Question (13) (you hear the following statement once)

Usually Mr. Parkins drives to work. But one day, his wife wanted to use the car, so he took the train to work. After work, he looked for his car in the parking lot but he couldn't find it. He thought it had been stolen. Then he laughed. He remembered why he couldn't find his car. 
Question: What did Mr. Parkins remember? (you hear a question once) Answer: (you choose the correct answer from the choices written in the answer sheet)

1. His wife took the train.

2. He usually leaves his car in the parking lot.

3. His car might have been stolen.

4. His wife borrowed the car. 